\title{
The organization of central sterile supply departments
}

\author{
J. D. WELCH \\ From the Nuffield Provincial Hospitals Trust, London
}

The last few years have witnessed an increasing interest in organizing sterilization. Every new hospital now being planned in the British Isles includes provision for a central sterile supply department and many existing hospitals are also planning such departments. Several of these are likely to be opened within the next year or two. At the present rates of progress there will be few hospitals without central sterile supply departments by 1970 . All this cannot be done without a great deal of work. Invariably it has been the hospital pathologist who has taken the initiative in the planning, organizing, and running of these departments. It is appropriate therefore that space should be devoted to this subject in the Journal of Clinical Pathology. Several articles have recently appeared dealing with the organization of central sterile supply departments. An excellent article by V. D. Allison appears in the British Medical Journal of 10 September 1960, and gives an account of the pioneer work which has been done at Musgrave Park, Belfast. It is hoped that the article that follows will be complementary to that of Dr. Allison. For those more closely concerned with the design of central sterile supply departments reference may be made to the article appearing in the Architectural Journal of 7 July 1960.

\section{AMERICAN PRACTICE}

The original idea of concentrating the arrangements for sterilization in one department arose in the U.S.A., and, before considering British practice, it may be of value to take a quick glance at American methods. But this must be done against the background of American hospitals. These are in competition with each other for those patients who can afford to pay the high fees charged. American hospitals, therefore, are lavish and it is usual to provide the staff with anything that they may require for a particular procedure. But all this equipment is seldom used and appreciable waste results. Again, as the costs can be passed on to the patients, there is little incentive to achieve economy by organizing a proper work flow. In the U.S.A. it does not seem to be realized that a central sterile supply department should be run more like an efficient factory than like a hospital department. It is certain that under the conditions of a National Health Service central sterile supply departments must be able to practice and demonstrate more efficient methods than are common across the Atlantic.

\section{MEANS OF STERILIZING}

Before considering how central sterile supply departments should be run it may be of value to enumerate the means of effecting sterilization. So far as hospitals are concerned there are five possible methods: by chemical means, by irradiation, by using gases, by steam, by hot air.

CHEMICAL STERILIZATION This is far from sure; it takes a long time; it must be done wet. Although a number of new and improved chemicals have been produced, it will generally be agreed that since chemicals disinfect rather than sterilize they should be used only if no other methods are possible.

IRRADIATION Recent increases in the peaceful use of atomic energy have brought the possibilities of irradiation to the fore. Over more traditional methods irradiation has certain advantages. It is sure in operation. It does not require heat. But irradiation also has important disadvantages so far as hospital products are concerned. It turns glass brown and, in time, breaks up the fibres of textiles. But the chief disadvantage of irradiation is that to be economical in operation the product to be sterilized should be fairly standard and a vast initial capital outlay is necessary. Unfortunately hospital products for sterilization are far from standard. They are indeed of a highly variable nature. Many are of glass or are textiles. As all hospital authorities know too well. vast capital sums are hard to come by. It is concluded, therefore, that, although sterilization by irradiation has considerable advantages for large scale manufactured products, it is unlikely to be of much practical value in hospitals for some time to come. 
GASEOUS STERILIZATION This was developed in Germany and the U.S.A. during the second world war, the gas which proved most promising being ethylene oxide. But here again difficulties and disadvantages are apparent. To be properly effective ethylene oxide requires to be of a high concentration, and humidity and temperature need to be carefully controlled. Ethylene oxide at high concentration is highly explosive, so under hospital conditions it is usual to use a mixture of $20 \%$ ethylene oxide and $80 \%$ carbon dioxide. In such concentrations this gas is proving unreliable, although with increased experience and more reliable control improved results may be obtained. So far as hospitals are concerned, therefore, this gas is likely to be of more value for the sterilization of things which cannot be sterilized any other way. Heart-lung machines are a case in point. Gas is unlikely to prove a substitute for steam under pressure or hot air.

STEAM AND HOT AIR Steam under pressure is the classical agent for sterilizing most of the needs of hospitals. But, there are advantages in using hot air for certain articles such as syringes and instruments. As the uses of steam and hot air are dealt with fully in other articles in this issue further reference to them is not made in detail here, except to state that they are likely to remain the principal sterilizing agents used in hospitals for a long time.

\section{AIMS AND SCOPE OF CENTRAL STERILE SUPPLY DEPARTMENTS}

It is at the outset necessary to be perfectly clear as to what central sterile supply departments are intended to achieve. If this is not done these departments may find themselves being called upon to attempt all kinds of tasks for which they were never intended. The aims of central sterile supply departments are: First, to conduct hospital sterilizing practice so that it can be properly controlled and supervised, thereby contributing to a reduction in the incidence of hospital cross-infection, and second to take a measure of work off the nursing staff thereby giving them more time to devote to their patients.

A central sterile supply department should, therefore, be charged with the production of all the sterile requirements of the hospital it serves, other than pharmaceuticals, bedpans, urinals, and theatre surgical instruments. Pharmaceuticals are the responsibility of the pharmacist; it is impracticable to centralize the cleaning of bedpans and urinals; and so many surgical instruments are used in the theatres that it would be laborious and costly continually to transport them about the hospital.

\section{PACKAGING}

It will be appreciated that, even if pharmaceuticals, bedpans, and theatre surgical instruments are ex-o cluded from the tasks of central sterile supply depart-으 ments, the list of articles still requiring to be sterilized $\frac{\bar{\rho}}{\frac{}{\sigma}}$ remains a very long one, ranging from such things as $\stackrel{\mathbb{Q}}{\Omega}$ small spigots to large maternity packs. If such a variety of products are to be packed before they are sterilized (and it would be inadvisable to package? them after sterilization) then packaging methods $\overrightarrow{\vec{\omega}}$ must be considered. The method of sterilization will $\stackrel{\omega}{\circ}$ often be dictated as much by the way in which the용 article to be sterilized is packed as by the nature of $\vec{A}$ the article itself.

In the U.S.A. it is customary to employ a com- $\dot{-}$ posite pack for each surgical procedure and to enclose them in two layers of linen. Fig. 1 shows an American $\triangle$ composite pack. Such a pack contains everything $\vec{c}$ that the surgeon or nurse can require for a procedure, and necessitates the production of an excessive variety of packs, many of the sterilized items of which go backwards and forwards without being $\vec{\varphi}$ used. A simpler system is required under National Health Service conditions. If soft (disposable) and hard (returnable) goods are packed separately, the nurse can select what she wants for each particular $\sum_{5}$ procedure and a more flexible and economical system results.

SOFT PACKS Experiments have shown that the soft $\overrightarrow{\overrightarrow{0}}$ goods should be packaged in paper or in paper bags 3 and then be put into cardboard boxes. Two barriers? are thus provided to protect the sterile contents from? contamination. If one of the barriers is of as firm a substance as cardboard the package is also less likely? to be punctured. Fig. 2 shows a soft pack being 3 . prepared.

A list of suitable soft packs is given in Appendix A. $\frac{\rho}{3}$ This list is for general ward use only and will, of 0 course, require supplementing for particular specialties. All the packs mentioned in Appendix A, to- gether with surgical gloves etc., can best be sterilized by steam in autoclaves. They will not stand high N temperatures. (Full details about high-vacuum $\sim$ steam sterilization are given in the paper that deals specially with this subject on page 11.)

It may be helpful to include some remarks on the expected shelf life of soft goods sterilized and ${ }^{\circ}$ packaged in this way. The answer will, of course, $\stackrel{\mathbb{D}}{\oplus}$ depend as much on the conditions of storage as on ${ }^{-}$ the methods of packing. Provided that the conditions $\frac{0}{0}$ of storage are good, i.e., such as are met with in a $\overrightarrow{\mathbb{D}}$ clean utility room of a well-run ward or a theatre $\frac{?}{?}$ store room, the sterilized packs could probably be stored for a month without danger of contamina- 


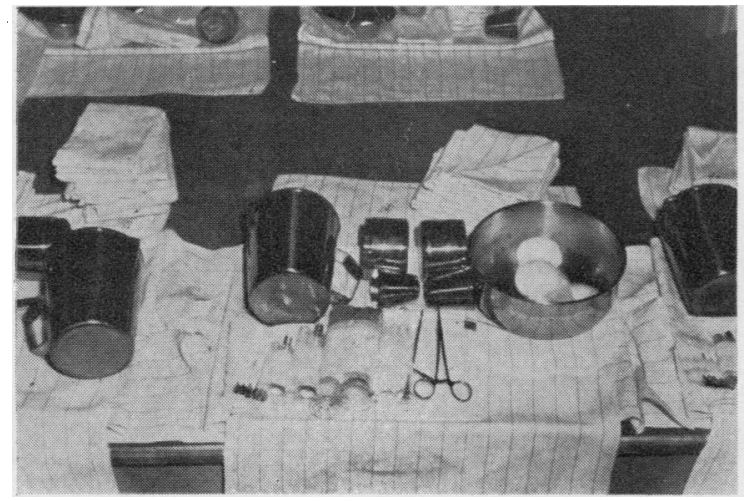

FIG. 1. A composite American pack. The large numbers of syringes, bowls, gallipots, and towels should be noted.

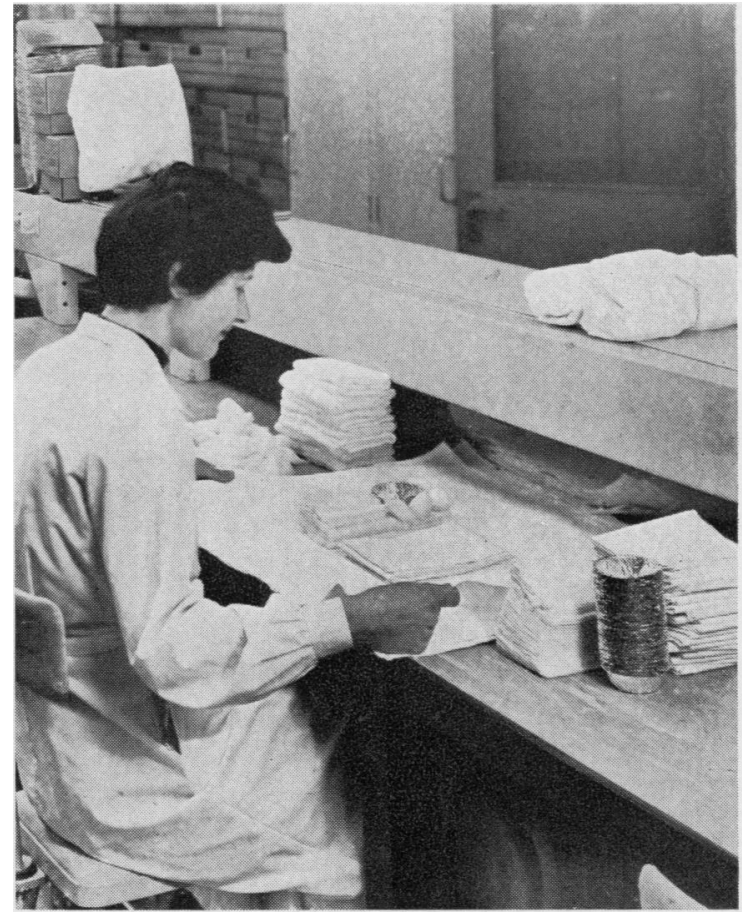

FIG. 2. A British soft pack being prepared. Everything is disposable. Compare with Fig. 1.

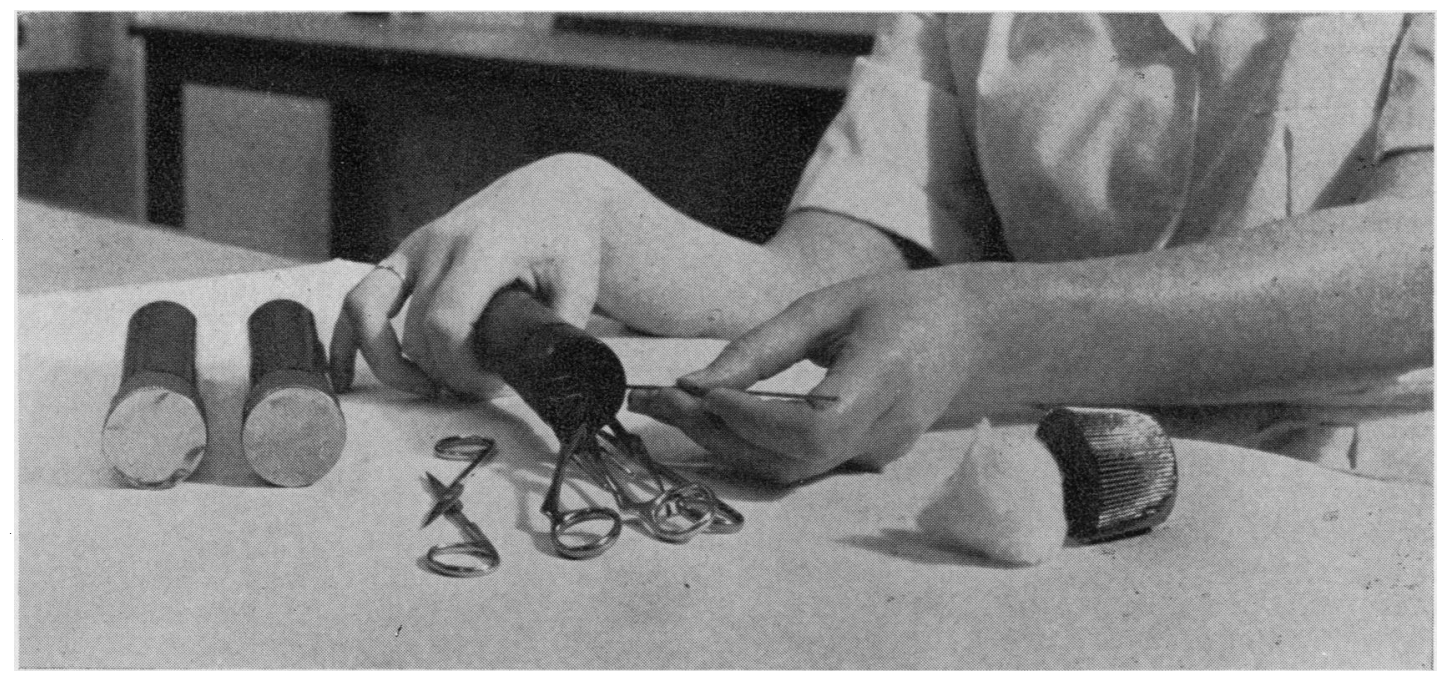

FIG. 3. A simple instrument pack. The design of the instruments to open out should be noted. 


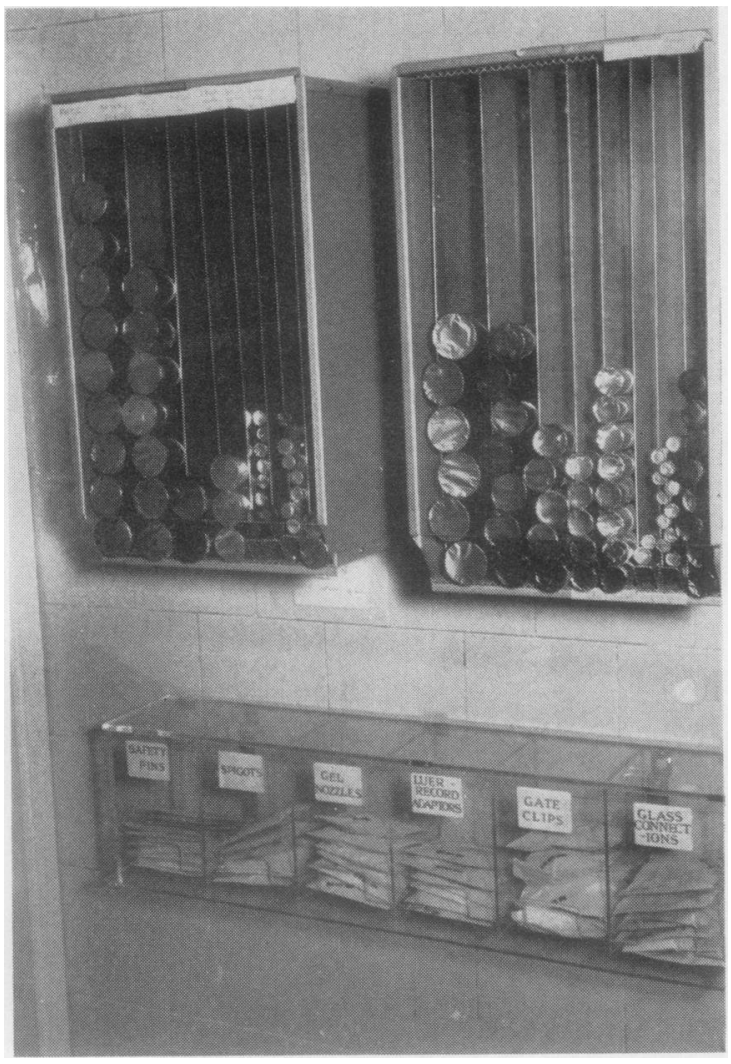

FIG. 4. Dispensers for syringes and small packed items.

tion. If a longer shelf life is required, as may be necessary for an emergency reserve stock, this can be met by using a third barrier of paper, either inside or outside the cardboard box. If three barriers are used in this way the packs can probably be stored in safety for as long as six months without resterilization. Shelf life can best be indicated to users by stamping each pack with an expiry date.

HARD PACKS If soft goods are packed in paper and cardboard, how should the hard goods, which are robust enough to stand sterilization by hot air, be packed? It has been found convenient to pack syringes and instruments in extruded aluminium tubes each sealed with an aluminium capsule. These aluminium tubes are widely used for the sterilization of syringes by hot air at $180^{\circ} \mathrm{C}$. The instruments required for ward procedures can all be fitted into a $20 \mathrm{ml}$. tube, provided that scissors, stitch removers, and artery forceps are re-designed so that they open out like a pair of travelling scissors. Such re-designing can easily be done by any instrument manufacturer and should not increase the cost of the instruments. 음 Fig. 3 is a photograph of an instrument pack.

A list of suitable instrument packs is given in $\stackrel{5}{+}$ Appendix B. This list is suggested for general ward 0 use and will require supplementing in the case of $\underline{\overline{0}}$. casualty departments and certain specialities. Full $\frac{\bar{\sigma}}{\overrightarrow{0}}$ details of sterilization of syringes and instruments by $\stackrel{\mathbb{\Omega}}{\Omega}$ hot air are given on page 39 .

As it is difficult to stamp syringe containers with expiry dates, a solution has been found by using dis- $?$ pensers which, by loading from the top and unload- $\vec{\omega}$ ing from the bottom, ensure that syringes and instru-. ments are used in proper rotation. This is adequate $\overline{8}$ for practical purposes, since the turnover of such $\overrightarrow{\vec{A}}$ items is generally more rapid than in the case of soft packs. Fig. 4 is a photograph of a syringe dispenser 8 and a dispenser for small packed items. If all the 0 articles mentioned above are to be provided packed $\stackrel{?}{\longrightarrow}$ and sterile for use in all departments, it follows that $c$ there is no need for the wards also to be provided with their own means of sterilization. Indeed it would be a mistake to do so since sterilization there cannot be controlled or supervised, and inefficient processing $\vec{\varphi}$ is thereby encouraged.

\section{ORGANIZATION OF CENTRAL STERILE SUPPLY DEPARTMENTS}

Plenty of evidence is already available to show that $\frac{0}{\circ}$ cross-infection may be spread through the agency of nurses' fingers. Yet nurses are continually called upon to rinse equipment which is known to be contaminated. This is inevitable if sterilization is undertaken on the wards. But when central sterile supply departments are available it should no longer be necessary for nurses to rinse a used syringe or instru- ment. It is, therefore, suggested that, as soon as an $\underline{3}$. instrument is used on a hospital ward, it should be $\delta$ disposed of as quickly as possible without the nursing staff undertaking any rinsing. This should reduce theo risk of cross-infection where it matters most, i.e., on the hospital wards. This will mean that there are three classes of equipment, the first being returned to central sterile supply departments will, at least, be potentially contaminated, i.e., 'dirty'. All used articles should, therefore, be washed in a wash-room N set aside for that purpose. No article should leave this room until it is clean and dry. It can then be moved in a clean and dry state to its own particular room for further processing: gloves to the gloves room and instruments and syringes to the instrument and syringe room. The second class of equipmento arriving in the department will be from manufacs] turers and laundries, i.e., it will be 'clean'. These two classes of equipment, the one originally 'dirty' buf now 'clean', and the manufactured disposables wilk 


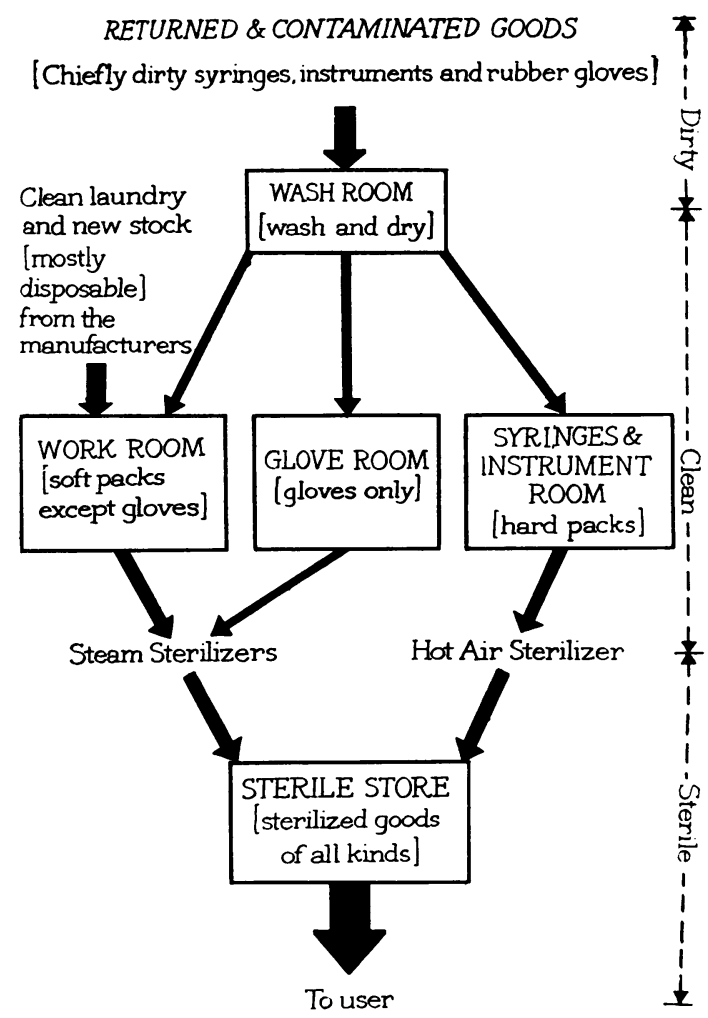

FIG. 5. Organization and work flow diagram.

then be married together, packed, and sterilized. The third class consists of all the sterilized equipment. The central sterile supply department requires to be organized to keep these three classes of equipment separate yet organized into a continual and logical work flow. The processes are illustrated in Fig. 5.

Experience has shown that once the goods have been packed and are ready for sterilization, it may be advantageous to store them temporarily in a nonsterile store. Here they can be held until required for sterilization. With modern high-speed autoclaves, sterilization takes very little time and, if packs are sterilized shortly before issue, there is less danger of them becoming 'time expired' before they are used.

\section{DISPOSABLES}

It is only within the last few years that attention has been given to disposable equipment. But the possibilities are now appreciated by many manufacturers as well as by the hospital authorities who are beginning to realize the heavy cost of re-processing. During the course of experimental work various disposable kinds of equipment have been tried.

DISPOSABLE SYRINGES These are already reaching the British Isles from America. The $2 \mathrm{ml}$. size, already packed and sterilized, retails at about $6 \mathrm{~d}$. The price of other sizes as and when they become available will vary directly with the size of the syringe. Such considerations will exclude, on ground of cost, all the larger sizes. Hospitals can process their own syringes, including a due proportion of the larger sizes, for an average of about $4 \mathrm{~d}$. or $5 \mathrm{~d}$. Jt follows that disposable syringes are unlikely to be an economic proposition under National Health Service conditions.

DISPOSABLE NEEDLES Nearly half the cost of the syringe processing mentioned above is attributable to processing the needle, which costs the hospital nearly 2d. each time it is processed. Disposable sterile needles are not yet on the market in England. But when they become available they are not likely to cost much more than $2 \mathrm{~d}$. In effect, therefore, the disposable sterile needle is a better economic proposition than the disposable syringe and its future in the hospital service looks promising.

PAPER In the past linen has been used extensively in hospitals for such purposes as drapes and hand towels. But this linen has to be laundered and then issued for use again. Laundering alone may cost as much as $2 \mathrm{~d}$. per article. Much of this cost and a lot of the labour involved in recirculating the linen would be saved if paper were to be used instead of linen. Manufacturers are aware of this and paper of greatly improved types is now being made available for hospital use. Fig. 2 shows a dressing pack of which most is paper. It would be a mistake to attempt to give details of the types of paper available for different purposes, since progress is so fast that any recommendations made would probably be out of date when published. Suffice it at this stage to say that paper is already available and probably better and cheaper than textiles for the following purposes: Instead of cotton wool balls for skin cleaning, instead of hand towels (sterile and unsterile), instead of surgical dressing towels, and as a packaging agent to prevent bacterial contamination. Those charged with the conduct of central sterile supply departments should keep in touch with developments in papers and see which are the most suitable for their purposes.

ALUMINIUM foll This is already widely used as a disposable substitute for the smaller sizes of stainless steel containers as also can be seen from Fig. 2. 
CARDBOARD BOXES These are now widely used as semi-disposable substitutes for hospital drums. They are lighter in weight, cheaper, and more effective in preventing bacterial contamination. They require, however, to be used only in conditions of dry steam. If hospital steam is wet-and this is not unusual-it will soon be demonstrated by the cardboard breaking up. In the experimental department at Addenbrooke's Hospital, Cambridge, no cardboard box has yet had to be replaced although many have been in use continuously for over six months.

PLASTICS Plastics have many uses either in a clean or sterile state. They are so cheap that they can be used once and thrown away. Used clean they are available as mattress and pillow covers to protect their contents from bacterial contamination; draw mackintoshes; gloves for such purposes as rectal examinations; and disposal bags for dirty dressings and household refuse. Sterilized by gamma-irradiation they are available as catheters and urological drainage bags.

\section{COLLECTION AND DELIVERY}

It is stated earlier that one of the aims of central sterilizing is to take work off the nursing staff. If the nursing staff were to undertake their own delivery and collection, the aims of the system would not fully be achieved. All central sterile supply departments should, therefore, undertake a collection and delivery service. Distribution systems are still the subject of experiment. They can be summarized under three heads: The 'one-for-one exchange' system, the 'milk-round' system, and the 'grocery' system.

'ONE-FOR-ONE EXCHANGE' SYSTEM Broadly this system consists of giving each ward a standard pannier containing their sterile supplies for 24 hours. Each 24 hours the pannier is exchanged for a full one and the unused supplies are taken back. The system has advantages. The wards cannot over-stock; packs cannot remain out long enough to become potentially contaminated, and exchange at the wards is speedily carried out. Yet the system also has considerable disadvantages. It cannot be used for all ward supplies, since these are too numerous. The very small and the very large items have to be delivered by a system of 'topping-up'. Exchange is therefore not so rapid as it might be. The panniers cannot themselves be sterilized and it seems doubtful whether they afford adequate protection to their sterile contents under adverse conditions. More work is also involved than is necessary since some of the contents of the pannier go backwards and forwards without being used. On balance it is not considered that the pannier system of delivery will prove suitable for widespread use.

'MILK-ROUND' SYSTEM This system, as its name implies, envisages delivery being undertaken by a system similar to that of milkmen, the delivery trolley being loaded with a standard load which is used to 'top-up' each ward on arrival. But experiments with this system have been disappointing. The requirements of most hospital wards are so varied that it requires a huge trolley to accommodate them all. This trolley, even with modifications, has proved too big to be manipulated satisfactorily in narrow hospital corridors. Work on this system of delivery has accordingly been abandoned and a solution sought by a third system.

'GROCERY' SYSTEM As its name implies, this is a system similar to that whereby a housewife receives her groceries. It is not without its drawbacks. In the first place it requires the ward to order supplies in advance. This involves the nurses in additional work which it would have been better to avoid. Secondly there is no way of preventing a ward from overordering; it is only possible to check it later. But the system has the advantage that ward orders can be made up in the orderly atmosphere of a central sterile supply department. Of the three methods the 'grocery' system involves spending least time delivering goods in ward passages. It is hoped, in time, to educate the nursing staff not to hoard unnecessary equipment.

\section{STAFF}

The importance of the staff of central sterile supply departments cannot be overemphasized. When the Nuffield Provincial Hospitals Trust published their booklet 'Present Sterilizing Practice in Six Hospitals' it was stated on page 52 'As always, the human element decides the quality of the service given.' This will always be the case so far as sterilization procedures are concerned. Of the staff the most im- o portant person is the supervisor. It is premature to $N$ attempt to suggest what technical qualifications the supervisor should hold. Some of those now doing $\underset{\sigma}{\sigma}$ such work are one-time theatre sisters, some are male nurses, some are laboratory technicians. The post $\stackrel{\circ}{c}$ calls for just those qualities of character and intellect which are always in demand. These are more important than technical qualifications. For the ordin- 0 ary work of the department women orderlies are $\vec{D}$

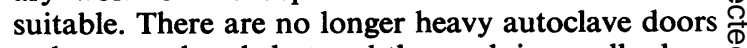
to be opened and shut and the work is usually done $\stackrel{\Phi}{\circ}$ more conscientiously by women. When departments? 
are fully operative and if the work is properly organized and mechanized, then a scale of labour as low as 1.5 orderlies per 100 beds to be served may be possible. This kind of a figure is, however, unlikely to be reached in the early stages of establishing a central sterile supply department.

$\cos \mathrm{T}$

It is appreciated that persons planning central sterile supply departments want to know prime and main- tenance costs. These departments have not yet been running long enough for reliable figures to be forthcoming.

I should like to thank the many people who have assisted and are still assisting in all the work that is being done at Cambridge. The staff at Addenbrooke's Hospital must be mentioned in particular. They have been most patient and conscientious in the various experimental work and have always been happy to try anything once. Considerable help has also been forthcoming from the development staff of the many manufacturers who have submitted their different products for trial.

\section{Appendix A: Contents of Four Dressing Packs}

\section{SMALL PACK}

Use: For minor dressings and similar procedures

Contents: 1 dressing towel -20 in. $\times 20$ in.

1 aluminium foil gallipot

2 gauze swabs -4 in. $\times 4$ in. $\times 8$-ply

2 wool balls.

\section{MEDIUM PACK}

Use: For such procedures as lumbar punctures, aspiration, catheterization, etc.

Contents: 2 dressing towels -20 in. $\times 20$ in. 2 aluminium foil gallipots 6 gauze swabs 4 in. $\times 4$ in. $\times 16-$ ply 6 wool balls.

\section{LARGE PACK}

Use: For major dressings and similar procedures

Contents: 2 dressing towels -20 in. $\times 20$ in. 1 gallipot, aluminium foil 4 gauze swabs -4 in. $\times 4$ in. $\times 16-$ ply 6 wool balls 2 wool squares -8 in. $\times 12$ in.
4 CotTONWOOL BALLS

Use: For supplementing any of the three standard dressing packs

Contents: 6 cottonwool balls

\section{Appendix B: Contents of Four Instrument Packs}

14 pairs of dissecting forceps

24 pairs of dissecting forceps 1 pair stitch scissors

1 pair clip removers
31 pair artery forceps 1 pair sinus forceps 1 probe

4 Intravenous cutting down set 